\title{
A combined MCDA - Monte Carlo Simulation approach for the evaluation of investment decisions on public transit.
}

\author{
Anastasia Roukouni ${ }^{\star}$ \\ Transport Systems Research Group, Faculty of Engineering, Building \\ "Edron", 6 $6^{\text {th }}$ fl., Aristotle University of Thessaloniki Campus, 54124, \\ Thessaloniki, Greece, natrouk@yahoo.gr*Corresponding author
}

\author{
Athanasios P. Vavatsikos \\ Democritus University of Thrace, School of Engineering, Dept. of \\ Production and Management Engineering, 12 Vas. Sofias st., 67100 \\ Xanthi, Greece, avavatsi@pme.duth.gr
}

\section{Maria Giannopoulou}

Democritus University of Thrace, School of Engineering, Dept. of Civil Engineering, 12 Vas. Sofias st., 67100 Xanthi, Greece,

klykostr@civil.duth.gr

\section{Francesca Medda}

University College London, Faculty of Engineering Science, Dept. of Civil, Environmental and Geomatic Engineering, Chadwick Building, Gower Street, WC1E6BT, London, UK, f.medda@ucl.ac.uk 


\begin{abstract}
As cities worldwide are projected to experience a noteworthy growth in population in the decades to come, additional strain is placed on many urban systems that are already at capacity. At the same time, public funds dedicated to transportation are experiencing vital cuts, creating this way considerable problems and forcing transportation specialists to investigate new ways of meeting this financial challenge; a set of options comes under the umbrella term "Value Capture". In this context, the objective of the present paper is to develop a Multicriteria Decision Analysis (MCDA) evaluation framework for the selection of the most efficient value capture financing mechanism for urban investment on transportation infrastructure and more importantly, to conduct a comprehensive sensitivity analysis in order to examine the stability and thus efficiency of the obtained results. The MCDA method used is the Analytical Hierarchy Process (AHP), while for the sensitivity analysis Monte Carlo Simulation is used. The application of Monte Carlo Simulation revealed very interesting pathways concerning the level of ambiguity and uncertainty of the results.
\end{abstract}

Keywords: Multicriteria Decision Analysis, Monte Carlo Simulation, Urban Public Transportation, Value Capture Finance

Biographical notes: Anastasia Roukouni holds a diploma from the Department of Rural and Surveying Engineering of the Aristotle University of Thessaloniki (AUTh), Greece, and an MSc in Transport from Imperial College London and UCL. She has recently (2016) completed her PhD in the field of Transport Economics (AUTh), under a State Scholarships Foundation (IKY) Fellowship of Excellence - Siemens Program (2012 - 16). She currently works as a Research Associate at the Transport Systems Research Group (AUTh). Her research and academic activity comprises issues related with Transportation Planning, Financing of Transportation Infrastructure, Value Capture Finance, Multi - Criteria Decision Analysis, Land use - Transportation Interaction, Evaluation Methods, GIS etc.

Athanasios P. Vavatsikos serves as a Lecturer in Spatial Decision Support Systems at the Department of Production \& Management Engineering, Democritus University of Thrace, Greece. He received the Diploma in Engineering degree (Dip.Eng.) from the Department of Civil Engineering and the Doctoral degree (Ph.D.) from the Department of Production \& Management Engineering, Democritus University of Thrace, Greece. His research interests focuses on MultiCriteria Spatial Decision Support Systems, Spatial Analysis and Planning, Multi-Criteria Decision Analysis, GIS.

Maria Giannopoulou is Associate Professor in Urban and Regional Planning at the Department of Civil Engineering, Democritus University of Thrace, Greece. Her research focuses on Spatial Analysis and Planning, Multi-criteria Decision Analysis, GIS, Special Topics in Urban Planning etc..

Francesca Medda is Full Professor in Applied Economics and Finance at the University College London, and she is the Director of the UCL QASER Laboratory. Her research focuses on Innovative Financial Instruments, Smart Cities Innovation, Infrastructure Investments, Risk Analysis. 


\section{Introduction}

An efficient public transport system is undoubtedly a major success factor for every city. Despite the fact that urban mass transit systems have a significant role in maintaining a sustainable urban economy, these systems are often underfunded (International Transport Forum, 2013). As the economic and credit crisis and its associated consequences has lead to an extended shrinkage of public resources dedicated to transportation nowadays, a gap is created between urban transportation system's requirements and the existing financing means to fulfil them. Urban and transport planners are therefore invited to think creatively in order to bridge this gap. Developing affordable, economic viable and people-oriented transport systems, depends on the use of a comprehensive and integrated approach to policy-making and decision-making (UN - HABITAT, 2013). In the search of alternative and innovative mechanisms and instruments to meet this financial challenge, a set of options comes under the umbrella term "Value Capture". The basic notion of value capture is that a part of the increase in land value that results from urban investments in infrastructure could be "captured" in order to recover the capital costs of the investment or/and reinvest in the area. Value Capture has been used increasingly as a tool for financing high cost public transport systems such as rail transit (Medda, 2012).

Almost all decisions to be taken in life are inevitably intertwined with various criteria that more or less have to be taken into account. The decision - making process related to transportation planning issues -and particularly transportation policy issues- is intrinsically complex due to the fact that, in addition to the large number of factors (both quantitative and qualitative) involved, there are usually many alternative scenarios to be examined. These alternative scenarios have to be evaluated, in order to choose the optimal solution for each specific case, according to the established criteria. The situation becomes further complicated when the policy in question concerns the rather sensitive issue of infrastructure financing/funding. Moreover, a large number of actors are involved in the decision making process; these actors usually come from different backgrounds and have different objectives, interests and aspirations. Multicriteria Decision Analysis (MCDA) has emerged as a robust methodology when dealing with multifaceted problems, as it allows incorporating the views of many different stakeholders and it facilitates the alignment with strategic transport policy objectives by using non - monetary/non - quantifiable criteria which nevertheless have a critical role on the final decision. 
Author

In this context, the objective of the research presented herein is to develop a MCDA evaluation framework for the selection of the most suitable value capture financing mechanism for urban investment on transportation infrastructure and more importantly, to conduct a comprehensive sensitivity analysis in order to examine the stability of the results and reveal potential ambiguities. The MCDA method used is the Analytical Hierarchy Process (AHP) while for the sensitivity analysis, Monte Carlo Simulation is used. Monte Carlo simulation allows incorporating into the evaluation process the inherent risk associated with the final AHP output. The suggested methodological approach is applied to a real-world case study: Crossrail Project in London, UK.

\section{MCDA in Transportation and Finance - The role of AHP}

One of the most commonly multicriteria decision analysis methods used in transportation research field is the Analytic Hierarchy Process (AHP). Vargas (1990) and Vaida and Kumar (2006), gathered a large number of publications which involve the use of AHP. The researchers underline that although there is a sound geographical coverage all over the world, the USA appears to be the country where the majority of interdisciplinary AHP applications have taken place so far. A very recent and comprehensive bibliographical review regarding the use of MCDA methods on transportation - related projects between 1985 - 2012 was made by Macharis and Bernardini (2015), who reviewed 276 publications. According to them, the predominance of AHP is clear, as it is employed in $33 \%$ of the examined cases. Some of the most contemporary applications of the method include the following: Nosal and Solenka (2014) use AHP in order to achieve the integration of the urban public transit system with demand management. Mosadeghi et al. (2015) carry out a comparative analysis of the use of AHP and AHP with incorporated fuzzy - data logic to assist decision - making in land - use - transportation planning, while Shiau (2013) applies AHP to assess sustainable transport strategies for Taiwan provinces, based on their degree of urbanization.

AHP is also a preferred approach when addressing financing issues. According to Spronk et al. (2005), the use of MCDA in financial decision making presents the following advantages: it allows dealing with multifaceted evaluation problems by incorporating quantitative as well qualitative criteria in the evaluation process, and at the same time it suggests a reliable, transparent, practical and adaptable approach. Among all the applications related to financial decisions that are examined in their study, AHP methodology has a leading role. The authors highlight that due to the aforementioned benefits, the future of MCDA methods in the field of financial management appears auspicious. This suggestion is in line with the view of Zopounidis (1999), who nevertheless emphasizes that the delivery of this promising future relies heavily on the evolution of specialized, user - friendly computerized multicriteria decision support systems. Fereira et al. (2011) argue that another significant strength of MCDA tools in the field is that they help reaching compromising solutions among decision makers, especially in cases when the existence of many different and even conflicting objectives impede the emergence of one optimal solution to satisfy all. Zopounidis and Doumpos (2002) state that using MCDA techniques to overcome the narrow and rather limiting optimization framework, which has been a common practice for years, is a comprehensive and sensible choice. 
Steuer and $\mathrm{Na}$ (2003) have gathered and classified 265 references, between 1955 and 2001 , regarding the contribution of MCDA techniques in the field of finance. This bibliographical survey is updated by Zopounidis et al. (2015), who were motivated by the indisputable progress that has been made in MCDA methods and tools during the last decade, in addition to the considerable changes that have occurred in the financing sector caused by the continuous globalization, rising markets' volatility, the launch of novel financial projects etc. They retrieved a total of 333 publications from all three main areas of finance: corporate finance, investments, and financial markets and institutions, covering the period 2002 - 2014. The authors conclude that the application of MCDA techniques in finance has a reasonable potential of being extended in the years to come.

\section{Methodological Framework}

\subsection{Analytical Hierarchy Process (AHP)}

Introduced by T.L. Saaty in the 1970s, the Analytic Hierarchy Process (AHP) is a non linear framework for addressing complex semi - structured decision - making problems. It is a scaling method for deriving priorities (weights) for a set of activities according to their importance. The method uses a hierarchic or network structure to represent the problem in question and then the relations within this structure are built using pairwise comparisons (Saaty, 1990). The method relies on three basic principles: a/the decomposition of the decision space to its fundamental elements, b/the comparative judgments and c/the synthesis of priorities (Saaty, 2005). The first principle is achieved by decomposing the decision problem with the aid of decision hierarchies. The hierarchies of objectives and sub-objectives that are created, attempt to reflect and incorporate the knowledge, experience and inspirations of the decision - makers regarding the specific problem (Banai-Kashani, 1989). Comparative judgments principle refers to the development of a sound and comprehensive base for deriving priorities among the parameters involved in the process. Local priorities are obtained by comparing each node against each of its peers with respect to its parent node. In order to assist the decision maker in carrying out the pairwise comparisons, Saaty created a nine point intensity scale of importance, known as the fundamental scale of preferences, ranging from equal importance (1) to extreme importance (9). Technically this is achieved by forming pairwise comparison matrices, where the ratio $\mathrm{a}_{\mathrm{ij}}$ assigned by the decision maker, expresses the dominance relation of the element in row $\mathrm{i}$ over the element in column $\mathrm{j}$. These preference scores are then subject to a synthesis process; relative priorities (weights) $\mathrm{w}$ are attained as the right principal eigenvector $\lambda_{\max }$ of the pairwise comparison matrix. In cases when the transitive property holds, the aforementioned matrix is consistent; however, in real - life problems this is a very rare and unlikely thing to happen. Therefore, AHP suggests a specialized index to investigate the existence and degree of inconsistency of judgments (Saaty, 1996).

According to Lepetu (2012), AHP is clearly a smart choice for eliciting weights when dealing with a decision making problem for the following reasons: it is a wellestablished procedure that can be repeated, it allows performing consistency checks, both quantitative and qualitative data can be used as input and it is appropriate for group 
decision making; in addition to that, it is applied widely in the academic literature. Moreover, AHP tends to highlight slight differences between the alternatives which decision - makers cannot always comfortably perceive (Mau - Crimmins et al., 2005). Roukouni et al. (2015) in their paper highlight synergies between AHP and ideal point methods. The present paper discusses in detail the concept of sensitivity analysis using the Monte Carlo simulation approach.

\subsection{Sensitivity analysis using Monte Carlo Simulation}

Despite its popularity as a decision support tool, AHP faces certain limitations among which is method's unavailability to provide alternatives' rankings when their scores are too close (Ataei et al., 2013); in addition that, Benke and Pelizaro (2010) notice that hierarchies of the deterministic AHP estimate weights using discrete values without providing measures of error or confidence. In the same direction, Feizizadeh et al. (2014) underline that MCDA models in general, produce results that are prone to uncertainties related to the nature of the decision making process. These uncertainties are usually associated with both limited information provided to the decision makers or the imprecision regarding their preferential system as well as the formation of the decision problem.

These drawbacks/limitations can be diminished by performing sensitivity analysis i.e. testing alternatives' ranking through changes in decision criteria priorities. Sensitivity analysis is an efficient method for investigating how the outcome of the analysis is differentiated with alterations in inputs, presumptions, or the way in which the analysis is built (Borgonovo and Pliscke, 2016). More specifically, sensitivity analysis assists in determining and classifying priorities, interpreting complex models, reducing/eliminating distortions of the analysis, pinpointing critical factors and revealing failures of a model (Ciuffo et al., 2014). It was developed during 1970s and several approaches have been proposed by researchers ever since (Sacco et al., 2014). The choice of which specific method of sensitivity analysis to use, strongly depends on the nature of the problem in question and the objectives/intentions of the research.

Having its origins in the 1940s, Monte Carlo Simulation arises as an appropriate tool to approach real-life problems that are challenging and demanding, if not unlike to be solved using purely analytical methods (Dagpunar, 2007). It consists of a series of computational algorithms that work by repeated sampling of a range of possible values in calculating a series of probability distributions (Barreto and Howland, 2006, Hu and Wang, 2015). It is particularly applicable in cases when, in handling intricate problems, a broad set of parameters is involved (Saltelli et al., 2004). Monte Carlo simulations allows decision problem solving under the consideration of uncertainty to all or to a part of decision variables through a large number of iterations. Baudry at al. (2014) provide an analytic discussion on AHP-based Monte Carlo simulation. In that concept Stochastic Multicriteria Acceptability Analysis (SMAA) introduces alternatives acceptability which obtains the probability that an alternative obtains a certain rank index (Lahdelma \& Salminen, 2016). First rank acceptability index can be seen as the Alternatives' Selectability Index (ASI) when for $r_{i}=1$ for every examined alternative $i$. This way, ASI expresses the level of confidence for each alternative to be ranked first and provides significant information with respect to the stability of the final outcome. In the 
aforementioned context of this research, Monte Carlo Simulation is performed to support sensitivity analysis through the following steps:

Step 1: Express each uncertainty using a triangular distribution function $[\mathrm{p}-\mathrm{u}, \mathrm{p}+\mathrm{u}]$ where $\mathrm{p}$ is the derived by AHP priority and consists its peak and $\mathrm{u}$ expresses the range of uncertainty under investigation.

Step 2: Construct the probability cumulative distribution for each uncertainty related with the global weights derived by the performance of AHP.

Step 3: Generate a random number in the range of [0-1] using uniform distribution for each one of the analysis criteria and alternatives performances.

Step 4: For every set calculate the global priority using the probability cumulative distribution estimated in step 2.

Step 5: Estimate alternatives priorities and find the most preferred one.

Step 6: Repeat the above steps for a significantly high number of iterations.

Step 7: Obtain ASI metric for every examined alternative

\section{Case analysis}

\subsection{Crossrail}

The approach described above is presented by means of an illustrative case: Crossrail, a new modern urban high speed rail system currently under construction in London, UK Having 37 stations, it will run for $118 \mathrm{~km}$ below central London, from Maidenhead and Heathrow in the west, to Shenfield and Abbey Wood in the east. When it becomes operative in 2018-19, the railway is anticipated to carry 1.5 million more commuters in less than one hour to London's strategic business locations and enhance London's rail capacity by approximately $10 \%$, while notably reducing congestion on the city's rail network. Furthermore, according to its impact study, Crossrail is expected to effectively support and boost development, having a considerable effect on investment decisions (GVA, 2012).

Figure 1 Crossrail route and stations and the three tax zones of Plan B (Roukouni et al., 2015)

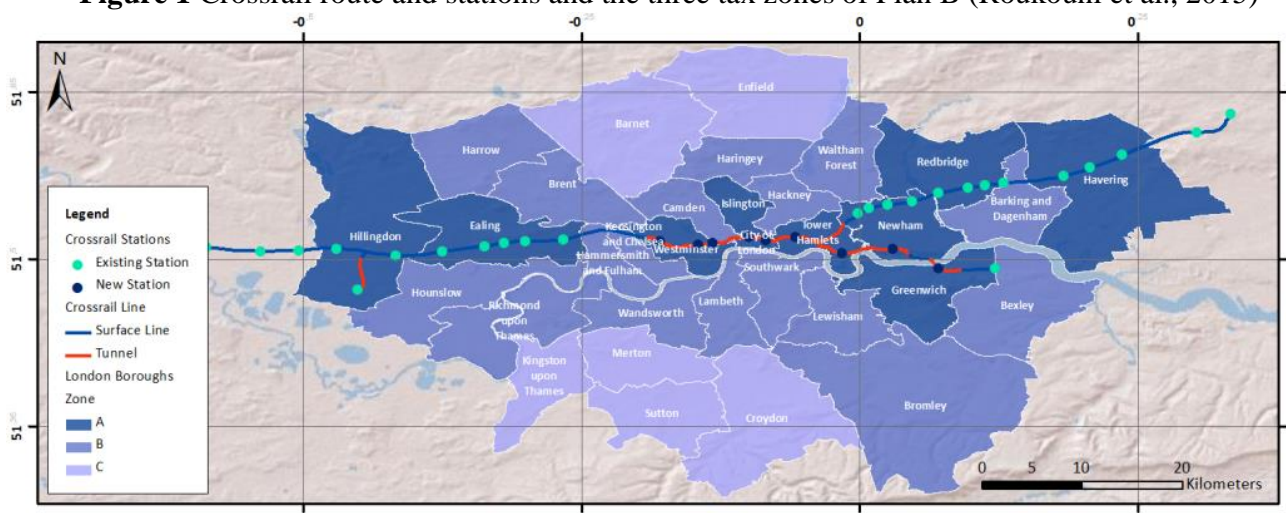


Author

The expected cost of the whole project is $£ 14.8$ billion, $£ 4.1$ billion of which will be generated by the Greater London Authority (GLA) through the Business Rate Supplement (BRS), a financing method based on the Value Capture concept. The GLA's BRS (Plan A) is compared to a proposed alternative financing scenario (Plan B) that could be used to replace it. Plan A involves a $2 \%$ flat tax on rateable values above $£ 55,000$ of non - domestic properties which are situated in all 32 London Boroughs and the Common Council of the City of London. Plan B consists of a combination of distance-based taxes: a modified version of the existing BRS scheme and a Stamp Duty Levy. Three zones are formed, based on the Boroughs' adjacency to Crossrail route (Figure 1) and the tax rates are differentiated accordingly. Moreover, more conservative growth rates of rateable values are used for the future revenue estimations (Roukouni et al., 2015).

\subsection{Evaluation Criteria}

The evaluation framework for the two scenarios was formed using the following assessment criteria and sub - criteria:

\section{Criterion C1: Efficiency}

- Subcriterion C1.1: Transportation efficiency (qualitative)

- Subcriterion C1.2: Dynamic Efficiency (qualitative)

Criterion C2: Equity

- Subcriterion C2.1: Estimated revenue from Zone A/ Total estimated annual transport and economic benefits in Zone A (quantitative)

- Subcriterion C2.2: Impact on Londoners' net personal income per Zone \% (quantitative)

- Subcriterion C2.3: Increase in total taxation due to the Crossrail tax in the poorest Boroughs (quantitative)

- Subcriterion C2.4: Distance weighted revenue (quantitative)

Criterion C3: Resilience/Sustainability

- Subcriterion C3.1: Estimated total revenue from non - residential taxpayers per Zone \% (quantitative)

- Subcriterion C3.2: Estimated revenue from Zone C/Total income of Zone C (quantitative)

- Subcriterion C3.3: Tax base of the scenario per Zone (quantitative)

- Subcriterion C3.4: Safety margin (quantitative)

- Subcriterion C3.5: Estimated total revenue (quantitative)

- Subcriterion C3.6: Plan duration (quantitative)

Criterion C4: Feasibility

- Subcriterion C4.1: Administration feasibility (qualtitative)

- Subcriterion C4.2: Political feasibility (qualitative)

A detailed description of the criteria and the rationale behind their selection, as well as the corresponding data sources is included in Roukouni (2011).

\section{Results and Discussion}

The existing strategy (Plan A) and the suggested alternative one (Plan B) are evaluated forming a 5-level hierarchy structure of goals and sub - goals. At the first level, 
the main objective of the analysis is set, while the fifth level comprises the examined scenarios. The intermediate levels are shaped by the selected criteria. The application of AHP methodology showed a predominance of Plan B on Plan A, by 53\%. As corroborated in the literature review earlier in this paper, in such cases when none of the alternatives appears to have a clear lead over the others, it is difficult to draw reliable conclusions regarding which solution is considered optimal. Therefore, the sensitivity analysis using Monte Carlo Simulation attempts to investigate how stable this result is. The number of iterations performed until convergence was reached is 5000. The factor of sensitivity was examined for a broad tolerance rate range between 5\% and 100\% (step every 5\%), using the triangular distribution, which is the most widespread probability distribution in cases when Monte Carlo Simulation is used. The objective is to calculate ASI for each alternative scenario aiming at expressing the stability of the preferable solution.

Apparently, the ASI for Plan A increases as the probability area of possible solutions becomes wider. This is due to the fact that criteria in which Plan A outperforms Plan B are gaining greater contribution to the final score of the examined scenarios. Nevertheless, the ASI of Plan B remains remarkably high during the whole process. For a $30 \%$ allowance, it is still higher than $80 \%$ and its evolution as the simulation range expands is rather smooth; the total spectrum of possible solutions (100\%) corresponds to a Plan B ASI of nearly 70\%. As illustrated in the diagram of Figure 2, regardless that the two lines which depict the ASIs appear to diminish their in between distance, it is ambiguous that Plan A ASI remains constantly lower. Hence, it can be confidently said that the AHP analysis result is consistent under different and miscellaneous circumstances; Plan B appears to be indeed the preferable financing option for partial financing of the Crossrail project.

Figure 2 Alternatives' Selectability Index after applying Monte Carlo Simulation

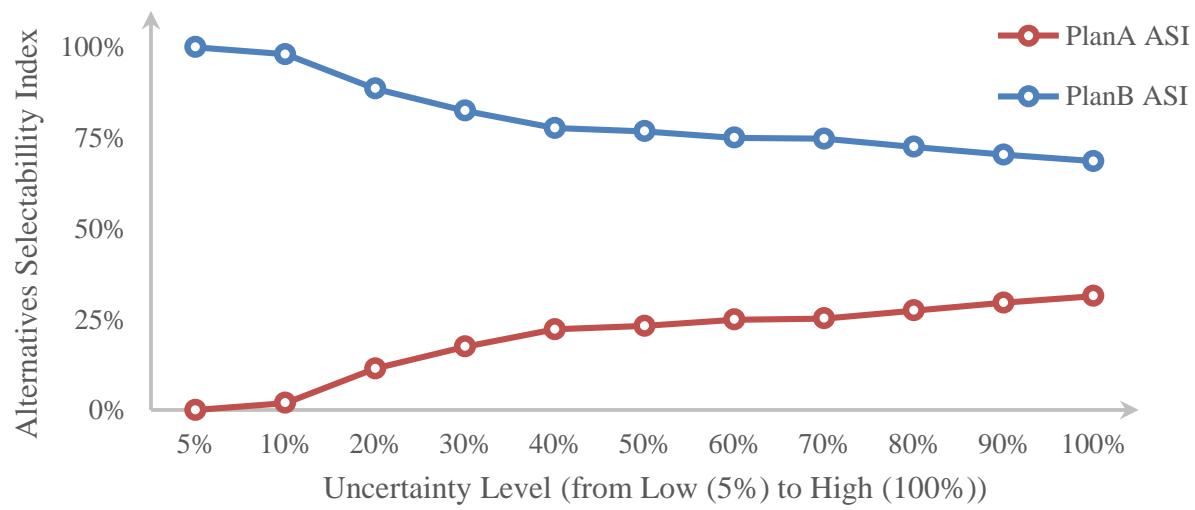

This observation is particularly interesting taking into account the project's scale; Crossrail is a transportation investment of significantly high cost and therefore the associated risk is expected to be unquestionably high as well. As a consequence, a really large number of actors and stakeholders are involved in the decision - making process, and as already mentioned previously, this brings on the table different and diverge backgrounds, aims, interests and endeavours. Thus, the very slight predominance of Plan B, which was the outcome of the AHP application, was not sufficient to obtain 
trustworthy results on which financing scenario is recommended as a preferable solution with respect to the examined criteria. Monte Carlo Simulation demonstrated that Plan B indisputably outbalances Plan A in the context of this analysis.

\section{Conclusions and Perspectives}

In conclusion, the application of the Monte Carlo Simulation, opened interesting pathways regarding the ambiguity and uncertainty of the AHP results. The innovative aspect of this project is that the combination of the Analytic Hierarchy Process and Monte Carlo Simulation has not been used so far, to best of our knowledge, to assess the potential of financing transportation projects and infrastructure through Value Capture. It is a useful and comprehensive approach proposed for decision makers who are trying to find innovative financing solutions for the city of the 20th century, compatible with sustainable and smart growth. At this stage, uncertainties are considered to appear with respect to criterion weighting elicitation. However, uncertainties are possible to occur in any alternative's per criterion performance's establishment. In that case, the number of demanded iterations and thus the computational load can be extremely high. Ideas for future research include the investigation of combinations of criteria and circumstances under which the Plan B is preferable, and the analysis of specific cases in which Plan A outbalances Plan B. This could be done by applying Monte Carlo Simulation to all stages of the analysis in addition to the final AHP output, i.e. to the pairwise comparison matrices. Moreover, other probability distributions, except from the triangular, could be tested in order to see how they fit the data and the more sophisticated Quasi - Monte Carlo algorithm could also be used for the analysis.

\section{References}

Baudry, G., Macharis, C. and Vallee, T. (2014) 'A range based Multi-Actor Multicriteria Analysis to incorporate uncertainty in stakeholder based evaluation processes', HAL, archives ouvertes, id: hal-01010513.

Borgonovo, E. and Pliscke, E. (2016) 'Sensitivity analysis: A review of recent advances', European Journal of Operational Research, Vol. 248, pp. 8669-887.

Benke, K.K. and Pelizaro, C. (2010) 'A spatial-statistical approach to the visualisation of uncertainty in land suitability analysis', Journal of Spatial Science, Vol. 55, No. 2, pp. 257272.

Ciuffo, B., Punzo, V. and Montantino, M. (2014) 'Global sensitivity analysis techniques to simplify the calibration of traffic simulation models. Methodology and application to the IDM car following model', Intelligent Transport Systems, Vol. 8, No. 5, pp. 479 - 489.

Dagpunar, J.S. (2007) Simulation and Monte Carlo: With applications in finance and MCMC, John Wiley \& Sons Ltd.

Feizizadeh, B., Jankowski, P. and Blaschke, T. (2014) 'A GIS based spatially-explicit sensitivity and uncertainty analysis approach for multi-criteria decision analysis', Computers \& Geosciences, Vol. 64, pp. 81-95.

Fereira, A.F.F., Spahr, R.W. and Pereira, A.M.J. (2011) 'New banking trends, MCDA and financial decisions: insights and a framework for retail banking', Banks and Bank Systems, Vol. 6, No.2, pp. 23 - 35. 
GVA (2012) Crossrail Property Impact Study, London, [online] http://www.crossrail.co.uk/assets/library/document/c/original/crossrail_property_impact_study _main-_small.pdf (accessed 5 January 2016).

Hu, Y. and Wang, F. (2015) 'Decomposing excess commuting: a Monte Carlo simulation approach', Journal of Transport Geography, Vol. 44, pp. 43-52.

International Transport Forum (2013) ' Funding Urban Public Transport: Case Study Compendium', OECD, [online] http://www.internationaltransportforum.org/Pub/pdf/13Compendium.pdf (accessed 5 January 2016).

Keeney, R.L. and Raiffa, H. (1976) Decisions with Multiple Objectives: Preferences and Value Tradeoffs, Wiley, New York.

Lahdelma, R. and Salminen P. (2016). 'SMAA in Robustness Analysis' In Doumpos M., Zopounidis C. and Grigoroudis E. (Eds.) Robustness Analysis in Decision Aiding, Optimization, and Analytics, International Series in Operations Research \& Management Science, Springer.

Lepetu, J.P. (2012) 'The use of analytic hierarchy process (AHP) for stakeholder preference analysis: A case study from Kasane Forest Reserve, Botswana', Journal of Soil Science and Environmental Management, Vol. 3, No. 10, pp. 237-251.

Macharis, C. and Bernardini, A. (2015) 'Reviewing the use of Multi-Criteria analysis for the evaluation of transport projects: Time for a multi-actor approach', Transport Policy, Vol. 37, pp. 177-186.

Mau-Crimmins, T., de Steiger, J.E. and Dennis, D. (2005) 'AHP as a means of improving public participation: a pre-post experiment with university students', Forest Policy and Economics, Vol. 7, pp. 501-514.

Medda, F.R. (2012) 'Land value capture finance for transport accessibility: a review', Journal of Transport Geography, Vol. 25, pp. 154-161.

Mohammad, A., Hashem, S. and Reza, M. (2013) 'Monte Carlo Analytic Hierarchy Process (MAHP) approach to selection of optimum mining method', International Journal of Mining Science and Technology, Vol. 23, No. 4, pp. 573-578

Mosadeghi, R., Warnken, J., Tomlinson, R. and Mirfenderesk, H. (2015) 'Comparison of Fuzzy AHP and AHP in spatial multi-criteria decision making model for urban land-use planning', Computers, Environment and Urban Systems, Vol. 49, pp. 54-65.

Nosal, K. and Solecka, K. (2014) 'Application of AHP method for multi-criteria evaluation of variants of the integration of urban public transport', Transportation Research Procedia, Vol. 3 , pp. 269-273.

Roukouni, A. (2011), "Evaluation of Business Rate Supplement as a Financing Mechanism for Crossrail", MSc Dissertation, Imperial College London and University College London, Supervisor: Medda, F.

Roukouni, A., Medda, F., Giannopoulou, M. and Vavatsikos, A. (2015) 'A Multi - Attribute Comparative Evaluation of Value Capture Financing Mechanisms: A Case Study' in Evaluation in Woltjer, J., Hull, A., Ruth, M. and Alexander, E. (Eds.): Integrated Land - Use management: Towards an Area Oriented and Place Evaluation for Infrastructure and Spatial Projects, Ashgate.

Saaty, T.L. (1996) Decision Making with Dependence and Feedback: The Analytic Network Process, RWS Publications, Pittsburgh, Pennsylvania.

Saaty, T.L. (1990) 'How to make a decision: The Analytic Hierarchy Process', European Journal of Operational Research, Vol. 48, pp. 9-26.

Saaty, T.L. (2005) 'The Analytic Hierarchy and Analytic Network Process for the measurement of intangible criteria and for decision making', in Figuera, J., Greco, S. and Ehrgott, M. (Eds.): Multiple Criteria Decision Analysis: State of the Art Surveys, International Series in Operations Research Management Science, Springer.

Saltelli, A., Tarantola, S., Campologno, F. and Ratto, M. (2004) Sensitivity Analysis in Practice: A Guide to assessing scientific models, John Wiley \& Sons, Ltd. 


\section{Author}

Shiau, T.A. (2013) 'Evaluating sustainable transport strategies for the counties of Taiwan based on their degree of urbanization', Transport Policy, Vol. 30, pp. 101-108.

Spronk, J., Steuer, R.E. and Zopounidis, C. (2005) 'Multicriteria Decision Aid/Analysis in Finance', in Figueira, J., Greco, S. and Ehrgott, M. (Eds.): Multiple Criteria Decision Analysis: State of the Art Surveys, pp. 799-858. Springer Verlag, Boston, Dordrecht, London.

Steuer, R.E. and Na, P. (2003), 'Multiple criteria decision making combined with finance: A categorized bibliographic study', European Journal of Operational Research, Vol. 150, pp. $469-515$.

UN - HABITAT (2014) 'The economics and financing of urban mobility' in Planning and Design for Sustainable Urban Mobility: Global Report on Human Settlements, United Nations Human Settlement Program [online] file:///C:/Users/mydell/Downloads/3503_alt.pdf (accessed 5 January 2016).

Vaidya, O.S. and Kumar, S. (2006) 'Analytic hierarchy process: an overview of applications', European Journal of Operational Research, Vol. 169, pp. 1-29.

Van Slyke, R.M. (1963) 'Letter to the Editor-Monte Carlo Methods and the PERT Problem' Operations Research, Vol. 11, No. 5

Vargas, L.G. (1990) 'An overview of the analytic hierarchy process and its applications', European Journal of Operational Research, Vol. 48, No. 1, pp. 2-8.

Zopounidis, C. (1999) 'Multicriteria decision aid in financial management', European Journal of Operational Research, Vol. 119, pp. 404 - 415.

Zopounidis, C. and Doumpos, M. (2002) 'Multi-criteria Decision Aid in Financial DecisionMaking: Methodologies and Literature Review', Journal of Multi - criteria Decision Analysis, Vol. 11, pp. 167 - 186.

Zopounidis, C. Galariotis, E., Doumpos, M., Sarri, S. and Andriosopoulos, K. (2015), 'Multiple criteria decision aiding for finance: An updated bibliographic survey', European Journal of Operational Research, Vol. 247, pp. 339 - 348. 
Title

\section{RESPONSE LETTER}

We would like to thank the reviewers for their constructive comments and their valuable contribution in improving our paper's potential. Our detailed response to their comments is provided in the following table.

\begin{tabular}{|c|c|c|}
\hline$\#$ & Reviewer Comment & Authors' Response \\
\hline & Reviewer A & \\
\hline 1 & $\begin{array}{l}\text { The author(s) examine a very interesting problem } \\
\text { with a high impact in real life. }\end{array}$ & $\begin{array}{l}\text { We would like to thank the } \\
\text { reviewer for this comment. }\end{array}$ \\
\hline 2 & $\begin{array}{l}\text { Although the combination of the AHP method } \\
\text { with Monte Carlo simulation seems to be an } \\
\text { interesting approach in this paper the way that } \\
\text { this combination is done is not clear at all. }\end{array}$ & $\begin{array}{l}\text { A small relevant paragraph } \\
\text { to clarify the point raised by } \\
\text { the reviewer was added in } \\
\text { pages } 5-6 \text { of the revised } \\
\text { manuscript. }\end{array}$ \\
\hline 3 & $\begin{array}{l}\text { The evaluation criteria presented in section } 4.2 \\
\text { are not clear and it is not explained why these } \\
\text { criteria were selected. }\end{array}$ & $\begin{array}{l}\text { A small relevant paragraph, } \\
\text { providing explanation about } \\
\text { the reason why this happens, } \\
\text { was added in the end of } \\
\text { page } 7 \text { of the revised } \\
\text { manuscript. }\end{array}$ \\
\hline 4 & $\begin{array}{l}\text { Additionally no table is given describing the } \\
\text { ranking of each criterion. }\end{array}$ & $\begin{array}{l}\text { We avoided the inclusion of } \\
\text { a table indicating the } \\
\text { sources of the data used, } \\
\text { due to space limitations (the } \\
\text { paper should not exceed } 10 \\
\text { pages in length; therefore we } \\
\text { chose to focus on the } \\
\text { significant aspects of it and } \\
\text { eliminate including many } \\
\text { details on the criteria, as we } \\
\text { consider that this would not } \\
\text { add any substantial } \\
\text { information to the paper's } \\
\text { objectives and scope). }\end{array}$ \\
\hline
\end{tabular}


Author

\begin{tabular}{|c|c|c|}
\hline 5 & $\begin{array}{l}\text { The steps presented in section } 3.2 \text { are not } \\
\text { explained well and a numerical example that } \\
\text { illustrates the proposed algorithm is missing. }\end{array}$ & $\begin{array}{l}\text { These steps consist standard } \\
\text { MCS procedures to assist } \\
\text { sensitivity analysis or DMs } \\
\text { vagueness }\end{array}$ \\
\hline 6 & & Please see Comment 5. \\
\hline 7 & $\begin{array}{l}\text { The same question holds for each step in Section } \\
\text { 3.2. }\end{array}$ & Please see Comment 5. \\
\hline 8 & $\begin{array}{l}\text { Additionally the result is only a graph in which } \\
\text { there are no titles for each axis. }\end{array}$ & $\begin{array}{l}\text { Titles were added to the axes } \\
\text { of the graph, as requested } \\
\text { by the reviewer. }\end{array}$ \\
\hline 9 & $\begin{array}{l}\text { Reviewer B } \\
\text { The only revisions related to } \\
\text {-- more clarity on criteria used in simulation }\end{array}$ & $\begin{array}{l}\text { Please see the last sentence } \\
\text { of Section } 4.2 \text { of the revised } \\
\text { manuscript; a detailed } \\
\text { description of the criteria } \\
\text { used is avoided due to } \\
\text { space limitations (the paper } \\
\text { should not exceed } 10 \text { pages } \\
\text { in length; therefore we chose } \\
\text { to focus on the significant } \\
\text { aspects of it and eliminate } \\
\text { including many details on the } \\
\text { criteria, as we consider that } \\
\text { this would not add any } \\
\text { substantial information to the } \\
\text { paper's objectives and } \\
\text { scope). }\end{array}$ \\
\hline 10 & $\begin{array}{l}\text {-- limitations of this method and further research } \\
\text { topics }\end{array}$ & $\begin{array}{l}\text { A small paragraph regarding } \\
\text { the limitations of the method } \\
\text { was added in the } \\
\text { Conclusions section. }\end{array}$ \\
\hline
\end{tabular}




\begin{tabular}{|c|c|c|}
\hline & Reviewer C & \\
\hline 11 & $\begin{array}{l}\text { Reference regarding relevant applications using } \\
\text { same methodology should be added. }\end{array}$ & $\begin{array}{l}\text { References regarding } \\
\text { relevant publications were } \\
\text { added (please see page } 5 \text { of } \\
\text { the revised manuscript). }\end{array}$ \\
\hline 12 & $\begin{array}{l}\text { Please make sure that the author publication in } \\
2015 \text { is not similar with this paper. }\end{array}$ & $\begin{array}{l}\text { Please see the last part of } \\
\text { Section } 3.1 \text { of the revised } \\
\text { manuscript, where the } \\
\text { differences between the two } \\
\text { publications is explained. }\end{array}$ \\
\hline 13 & $\begin{array}{l}\text { In the section of listing the assessment criteria } \\
\text { and sub - criteria, more details and explanations } \\
\text { are required. }\end{array}$ & $\begin{array}{l}\text { Please see the last sentence } \\
\text { of Section } 4.2 \text { of the revised } \\
\text { manuscript; a detailed } \\
\text { description of the criteria } \\
\text { used is avoided due to } \\
\text { space limitations (the paper } \\
\text { should not exceed } 10 \text { pages } \\
\text { in length; therefore we chose } \\
\text { to focus on the significant } \\
\text { aspects of it and eliminate } \\
\text { including many details on the } \\
\text { criteria, as we consider that } \\
\text { this would not add any } \\
\text { substantial information to the } \\
\text { paper's objectives and } \\
\text { scope). }\end{array}$ \\
\hline 14 & $\begin{array}{l}\text { The measure and the unit of each criterion have } \\
\text { to be clarified, for example what is the measure } \\
\text { of administration feasibility on criterion C } 4 \text { ? }\end{array}$ & $\begin{array}{l}\text { A clarification was added } \\
\text { after each criterion, stating } \\
\text { whether the criterion is } \\
\text { measured in quantitative or } \\
\text { qualitative terms. } \\
\text { Administration and political } \\
\text { feasibility are both evaluated } \\
\text { using qualitatively, using the } \\
\text { 9-point Saaty scale. }\end{array}$ \\
\hline 15 & $\begin{array}{l}\text { Also the resources for each data used to } \\
\text { calculate each criterion and sub-criterion value } \\
\text { have to be given. }\end{array}$ & $\begin{array}{l}\text { Please see Comment 13; we } \\
\text { avoided the inclusion of a } \\
\text { table indicating the sources } \\
\text { of the data used, due to } \\
\text { space limitations. }\end{array}$ \\
\hline
\end{tabular}


Author 